Lachman and Chris Henney, provided the scientific drive and attraction for a highly productive and creative stable of biologists, protein chemists and molecular biologists at Immunex. Industry is now the unabashed centre for many of the rapid advances in cytokine biology. Certainly the rapid identification of cytokines and their receptors, their cloning and ultimately production for clinical trials has largely become the domain of Immunex and others of their ilk. Rapid proliferation of biotechnology companies in the United States has become the envy and model for similar starts-up companies overseas and it is likely that such outfits capable of generating sufficient funds for applied research and ultimately their application clinically will be the main province of biotechnology. It should not be surprising then that Gillis and coeditor Ammann from Genentech should have chosen to develop another forum for their efforts.

Thus we have this new journal. The assembled editorial facesheet reads like a Who's Who of biotechnology with 10 out of the 24 individuals representing companies such as Immunex, Genentech, Genetics Institute, Cetus Corporation, DNAX Research Institute and Amgen. The need to have a specialized forum however, as initially conceived by the editors for a single source of articles evolving around biotechnology, is belied by the concurrent rapid development of its competitors. Joining the Journal of Immunotherapy are other new journals, including Biotherapy and Molecular Biotherapy (reviewed in Nature last year) European Cytokine Network, Cytokine (see page 465) and Human Gene Therapy.

Out of 21 articles in the first four issues, 16 deal with growth factors and cytokines and 7 are from either biotechnology firms exclusively, or coauthored by an individual representing one of the firms. The journal consists largely of reviews and occasional original articles, with a single issue of the four focusing on summaries from an Illinois Cancer Council Symposium. Most of them are clear and well written but I suspect are still not yet the premiere groundbreaking articles (I wrote one of them) generated within or without the biotechnology industry. Although the publisher indicates that contributions to the journal are published free of charge, the cost to individuals at about $\$ 0.50$ per page is about double that of the Journal of Immunotherapy.

As any good drug-house knows, one has to develop 10 new drugs for one wildly successful one to make it in the market-place. The same may be true with the recent proliferation of biotherapy and biotechnology journals. This particular one seems to be most clearly spawned of itself, and to its credit, is the only one to have a representative from the distaff side as an associate editor. Susanna Cunningham-Rundles indicates that the main focus for the journal is to publish the best-quality manuscripts possible, but also early and not yet complete stories of the application of cytokines, as well as important negative studies.

With 30,000-100,000 genes within the human genome having evolved to potentially find themselves listed on the spreadsheet of a biotechiology firm, and only a fraction of them developed, the future is bright indeed for these products to become ultimately the mainstay of

\section{TG or not TG?}

\section{Steve S. Sommer}

DNA Sequence: The Journal of DNA Sequencing and Mapping. Editor Bart Barrell. Harwood Academic. 6/vol. US and Canada \$293, elsewhere Dfl. 644.

WE are nice enough to lawyers, used-car salesmen and 'sequence jocks' when we need them, but deep down we feel morally superior. Sure, sequencers can still get a paper into Nature if the God of sequence homology bestows an unexpected and revealing pattern, but in general, sequencing is now routine and of little intellectual challenge. Hence, increasingly, established journals in the biological sciences either do not publish sequencing papers or restrict the length of those that are published, particularly when there are no additional experimental data.

If the above strikes a responsive chord, read no

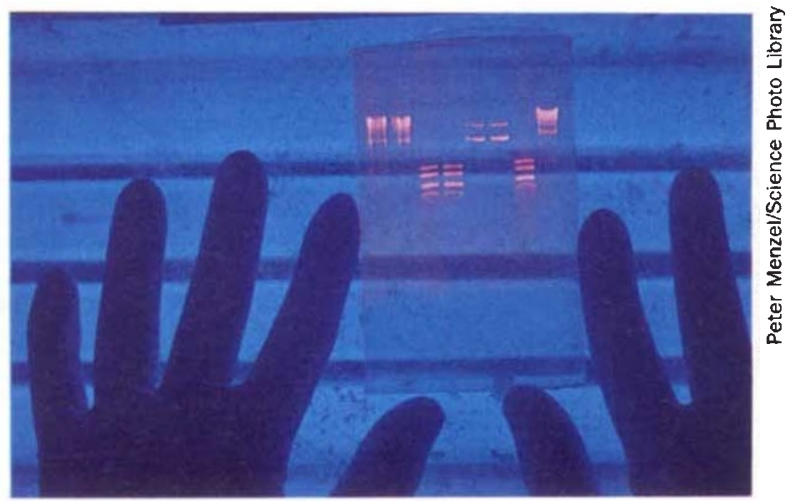

DNA banding pattern in an electropheresis gel. The pattern in pink fluorescence is revealed under ultraviolet light.

further. If, on the other hand, you are impressed with the ever increasing number of insights provided by an educated analysis of sequences, DNA Sequence may be for you. This new journal publishes mapping data useful to future DNA sequencing, DNA sequence data in full, new sequencing procedures and allied techniques, computer methods to analyse DNA sequences, and compilations of sequence motifs. Emphasis is given to papers that include methodology and collation of sequences. Highquality reviews are invited. The journal provides a forum for the exchange of research experience and advice through a 'Letters to the editor' section. DNA Sequence is based at the Medical Research Council's Laboratory of Molecular Biology in Cambridge, United Kingdom. Bart Barrel and clinical therapeutics. Certainly with six hundred billion dollars spent in the United States alone for health care in 1990 , and an anticipated 1.5 trillion by the such products would seem to exist. The question of the viability of biotechnology journals and the industries that generated them will largely be dependent on our ability to afford them and their ability to replace other costly technologies (and journals).

Michael T. Lotze is in the Department of Surgery, University of Pittsburgh School of Medicine, 497 Scaife Hall, Pittsburgh, Pennsylvania 15261, USA.

John Walker are the editor-in-chief and deputy editor, respectively. John Sulston and Alan Bankie are the mapping and sequence method editors, respectively. The US editor is Clyde Hutchinson III at the University of North Carolina.

The papers in the first four issues were diverse and a number of prominent laboratories were represented. A partial list of titles is perhaps the best way to give the reader a sense of the contents: 'A dictionary of transcription control sequences'; 'Sequencing with the large fragment of DNA polymerase I from Bacillus stearothermophilus'; 'Alterna-

tively spliced Hox -1.7 transcripts encode different protein products'; and 'Mapping DNA by stochastic relaxation: schedule for optional annealing'.

DNA Sequence may well serve the needs of a growing number of scientists who want a forum for all aspects of sequencing including methodology development, sequence analysis and compilation of sequence motifs. I sense that this journal will do well and I anticipate that it will soon spawn a companion journal, RNA Sequence, which in turn will spawn Codon and Untranslated Regions. Such is the nature of progress.

Steve S. Sommer is in the Department of Biochemistry and Molecular Biology, Mayo Foundation, Rochester, Minnesota 55905, USA.

NATURE $\cdot$ VOL $353 \cdot 3$ OCTOBER 1991 year 2,000, a large potential market for 